\title{
Uso de broncodilatadores en bronquiolitis: ¿sí o no?
} Bronchodilators in bronchiolitis: Yes or no?

Las infecciones respiratorias agudas (IRA) continúan siendo la principal causa de consulta en los primeros años de vida. Dentro de esta patología, la bronquiolitis es el cuadro clínico más frecuente. Ante la magnitud del problema que se repite año tras año, los países han adoptado diferentes estrategias para hacerle frente.

En Latinoamérica, Chile fue el primer país en presentar un programa específico al respecto. Este se basaba en identificar el problema clínico (ej.: croup, neumonía, síndrome bronquial obstructivo -SBO-), establecer la gravedad, instituir un tratamiento adecuado $y$, eventualmente, derivar de manera oportuna. ${ }^{1}$ En el caso del SBO, la gravedad era establecida por un puntaje clínico y el tratamiento inicial incluía salbutamol administrado vía inhalador de dosis medida (metered-dose inhaler; MDI, por sus siglas en inglés) con aerocámara y, eventualmente, oxígeno. Cabe destacar que, en este enfoque, los pacientes con bronquiolitis son incluidos dentro del SBO.

Esta estrategia fue muy exitosa, por lo que la adoptaron diferentes países de la región. Las actuales guías argentinas, chilenas y peruanas continúan enfocando la atención de los lactantes con IRA y sibilancias sobre la base del concepto de SBO y, por lo tanto, contemplando el empleo de broncodilatadores adrenérgicos vía MDI con aerocámara como "tratamiento de prueba".

La guía de bronquiolitis de la American Academy of Pediatrics (AAP) de 2006 también consideraba el uso de los broncodilatadores como una "prueba terapéutica". Sin embargo, en su última versión (2014), recomienda no incluir los broncodilatadores adrenérgicos como opción terapéutica. ${ }^{2}$ Los autores de la guía sostienen que, dada la fuerte evidencia que demuestra el no beneficio y que no hay un instrumento de medición bien establecido para determinar en forma objetiva la respuesta al tratamiento, los broncodilatadores no deben ser utilizados rutinariamente en bronquiolitis. Pero ellos mismos reconocen que "la población de niños con bronquiolitis incluidos en la mayoría de los estudios limita la habilidad de hacer recomendaciones para todos los escenarios clínicos".

Consideramos que la recomendación de la AAP de 2014 es opinable por los siguientes motivos: a) Todos los estudios aleatorizados realizados en bronquiolitis en los que los broncodilatadores no mostraron una mejoría significativa fueron desarrollados administrando el salbutamol vía nebulización y no vía MDI con aerocámara; ${ }^{3}$ es bien conocida la menor respuesta al salbutamol administrado vía nebulización que vía MDI con aerocámara. ${ }^{4}$ b) $\mathrm{Al}$ menos un estudio aleatorizado demostró que los niños menores de 1 año con crisis obstructivas que recibieron salbutamol vía MDI con aerocámara respondieron mejor (menor probabilidad de requerir hospitalización y mayor mejoría del puntaje clínico) que aquellos que lo recibieron vía nebulización. ${ }^{5} \mathrm{c}$ ) Si bien la mayoría de los niños con bronquiolitis aguda no van a desarrollar asma, hay un subgrupo de pacientes menores de un año en quienes la bronquiolitis es la primera manifestación de una crisis asmática, por lo tanto, se beneficiarán con una "prueba terapéutica" con salbutamol vía MDI con aerocámara.

A este hecho se suma que también existen diferencias en la definición de bronquiolitis. Por ejemplo, según el consenso italiano correspondiente, la bronquiolitis se restringe al primer episodio en un niño menor de 12 meses, ${ }^{6}$ mientras que las guías norteamericanas no lo limitan al primer año de vida y remarcan la presencia de sibilancias. ${ }^{2}$ Más aún, la guía británica de bronquiolitis señala que hay que pensar en un ataque precoz de asma más que en bronquiolitis si el episodio ocurre en niños cercanos a los 12 meses o más, que tengan sibilancias persistentes sin rales crepitantes, episodios de sibilancias recurrentes o historia familiar de asma. ${ }^{7}$ Esto indica que, con las definiciones de "bronquiolitis" en uso, no se puede descartar que no se trate de un lactante en su primer episodio de asma, especialmente, si se considera la elevada prevalencia de esta afección. Todo lo anterior pone en evidencia que la bronquiolitis es una enfermedad heterogénea en su cuadro clínico y que depende de diversos factores, como el virus patógeno y su interacción con el microbioma de la vía aérea, la respuesta inmune, la genética del huésped y factores ambientales. 8 . Por lo tanto, es muy probable que un mismo esquema terapéutico no sea lo más adecuado para tratar a todos los pacientes.

Además, no debe olvidarse que la estrategia utilizada en Argentina contempla la atención 
de los pacientes desde el punto de vista del SBO hasta los 2 años. Por lo tanto, es más probable que, junto con las bronquiolitis, se incluyan pacientes con asma en su primer episodio.

Independientemente de esta controversia que surge de la evidencia disponible, la experiencia en el manejo de esta enfermedad nos ha dejado algunos conceptos:

1. La mayor parte de los pacientes con esta enfermedad entran al sistema de salud desde el primer nivel de atención y, por lo tanto, las estrategias para su manejo deben contemplar esta realidad.

2. Es prudente categorizar a los pacientes con un esquema de tamizaje (puntaje clínico) que identifique a los que pueden ser asistidos ambulatoriamente en forma segura, a los que requieren ser observados durante algún tiempo y a los que demandan hospitalización inmediata. Las escalas de gravedad clínica utilizadas tanto en Chile como en Argentina son prácticas y se correlacionan adecuadamente con los rangos de saturación de oxígeno que requieren intervención ${ }^{10}$ y permiten evaluar la respuesta al broncodilatador

3. El oxígeno es el único tratamiento imprescindible cuando existe hipoxemia.

4. El empleo de salbutamol como tratamiento de prueba puede ser beneficioso y debe realizarse hasta que nuevos estudios generen evidencia concluyente (ej.: estudios aleatorizados con salbutamol vía MDI mas aerocámara vs. placebo), al menos mientras los programas de salud pública nacionales se basen en el concepto de SBO.

Sin embargo, también es importante recalcar que, si no hay respuesta al salbutamol, este debe ser suspendido. La falta de coraje para suspender un tratamiento broncodilatador una vez comprobada su ineficacia no debe impedir que algunos pacientes reciban un tratamiento efectivo ni limitar los recursos terapéuticos de los médicos del primer nivel de atención.

Prof. Dr. Fernando Ferrero

Departamento de Medicina,

Hospital General de Niños Pedro de Elizalde,

Buenos Aires.

Prof. Dr. José A. Castro Rodríguez

División de Pediatría, Escuela de Medicina, Pontificia Universidad Católica de Chile. http: / / dx.doi.org/10.5546/ aap.2018.5

Texto completo en inglés:

http:/ / dx.doi.org/10.5546/aap.2018.eng.5

Cómo citar: Ferrero F, Castro Rodríguez JA. Uso de broncodilatadores en bronquiolitis: ¿sí o no? Arch Argent Pediatr 2018;116(1):5-6.

\section{REFERENCIAS}

1. Girardi G, AstudilloP, Zúñiga F. El programa IRA en Chile: hitos e historia. Rev Chil Pediatr 2001;72(4):292-300.

2. RalstonSL, Lieberthal AS, MeissnerHC, etal. Clinical practice guideline: the diagnosis, management, and prevention of bronchiolitis. Pediatrics 2014;134(5):e1474-502.

3. Castro-Rodriguez JA, Rodriguez-Martinez CE, SossaBriceño MP. Principal findings of systematic reviews for the management of acute bronchiolitis in children. Paediatr Respir Rev 2015;16(4):267-75.

4. Castro-Rodriguez JA, Rodrigo GJ. Beta-agonists through metered-dose inhaler with valved holding chamber versus nebulizer for acute exacerbation of wheezing or asthma in children under 5 years of age: a systematic review with meta-analysis. J Pediatr 2004;145(2):172-7.

5. Rubilar L, Castro-Rodriguez JA, Girardi G. Randomized trial of salbutamol via metered-dose inhaler with a spacer versus nebulizer for acute wheezing in children less than 2 years of age. Pediatr Pulmonol 2000;29(4):264-9.

6. Baraldi E, Lanari M, Manzoni $\mathrm{P}$, etal.Inter-society consensus document on treatment and prevention of bronchiolitis in newborns and infants. Ital J Pediatr 2014;40:65.

7. National Institute for Health Care and Health Excellence. Bronchiolitis in children: diagnosis and management. NICE guideline [NG9]. London: NICE; 2015. [Acceso: 13 de octubre de 2017]. Disponible en: https: / / www.nice.org. uk/guidance/ng9/.

8. Dumas O, Mansbach JM, Jartti T, etal. A clustering approach to identify severe bronchiolitis profiles in children. Thorax 2016;71(8):712-8.

9. Mansbach JM, Clark S, Teach SJ, et al. Children hospitalized with rhinovirus bronchiolitis have asthmalike characteristics. J Pediatr 2016;172:202-4.

10. Coarasa A, Giugno H, Cutri A, et al. Validación de una herramienta de predicción clínica simple para la evaluación dela gravedad en niños con síndrome bronquial obstructivo. Arch Argent Pediatr 2010;108(2):116-23. 